\title{
Professional and practice development plans for primary care teams
}

\author{
Life after the postgraduate education allowance
}

$\mathrm{T}$

The spread between the best and the worst of the 10000 practices in the United Kingdom is wide. In a matter of minutes we can travel from paperless practices with integrated teams which have developed nurse practitioners, physiotherapy, and in house phlebotomy to those where the prescribing is suspect and the consultations perfunctory-all performed with the sole aids of prescription pads, sick notes, and unchecked sphygnomanometers. Like the gap between evidence and practice, there is a gap too between continuing medical education and professional and practice development.

Professional and practice development plans aim to fill that gap and are destined to replace the postgraduate education allowance. The concept is a direct result of the Chief Medical Officer's review of continuing professional development in general practice, which adds another surge of energy to the "corporate" rather than the "independent practitioner" vision of primary care. The review was a response to the criticism that the postgraduate education allowance has been based on an educational model which is "didactic, uni-professional and top-down," rarely involves the whole practice team, and shows little evidence of any "convincing benefits to patient care."

The postgraduate education allowance system, which enables general practitioners to obtain part of their income for, essentially, attending meetings, has a uniprofessional focus and allows doctors to play to their strengths rather than identify true educational needs. ${ }^{2}$ Although attempts have been made to allow self directed learning, the system is based on a discredited didactic model ${ }^{3}$ that has more often provided the pharmaceutical industry with a convenient marketing opportunity.

Although there is little detail yet, professional and practice development plans are clearly a hybrid approach which combines documented personal learning with an organisational development framework. As Stanton and Grant's review ${ }^{4}$ and other work ${ }^{56}$ confirms, "credit based" educational schemes do not lead to changes in behaviour or organisational improvements. Successful interventions contain features that predispose to, enable, and reinforce changethat is, that deliver information, rehearse behaviours, and provide reminders and feedback. Effective strategies also use contextual and motivational influences. to call for the construction of learning portfolios for all the practice team (doctors, nurses, and managerial staff) which take account of the development needs of the working unit as well as the individuals in it. ${ }^{2}$ The plans therefore combine a systems approach to change management with self directed learning. ${ }^{7}$ They represent a gradual shift away from individual to organisational performance as a proxy measure for quality. ${ }^{8}$ The involvement of patients could strengthen the process, ensure local responsiveness, and guard against the loss of personal care. ${ }^{9}$

Asking practices to construct development plans will have significant benefits. Teamwork will be required if the plans are to represent a consensus view about how best to deliver organisational priorities. Perhaps nurses should become responsible for immunisation procedures? $^{10}$ Should warfarin and lithium monitoring services be available? Does the appointment system provide reasonable access? Plans could become tools for measuring the achievement of priorities-a form of stepwise practice reaccreditation. By linking the professional development of individual practitioners to an organisational development strategy that recognises variable starting positions, professional and practice development plans could be the most effective lever for change in primary care yet devised. ${ }^{11}$

But there are traps for the unwary. Firstly, will the funding be combined for those disciplines that work together in primary care? General practitioners have grudgingly accepted the postgraduate education allowance system, but practice nurses and managers bemoan that their training and professional development is in a mess, restricted by staff budgets and the goodwill (or otherwise) of their general practitioner employers. Community nurses do have access to professional advice but struggle to obtain a slice of hard pressed trust budgets. Will the funds for the postgraduate education allowance be diverted to team development as a carrot for taking part? General practitioners will have less argument with the new development plans if postgraduate education allowance money is preserved within net income.

Ensuring multiprofessional educational accreditation is no easier, as anyone who has tried arranging joint training events will know. The accreditation system for the postgraduate education allowance is an open book compared with the various nursing board 
procedures, which seem unwittingly to block the development of interprofessional learning.

The system will need enough flexibility to include part time professionals and to recognise individual learning that may not always be based on organisational requirements. But the main concern centres on how, and by whom, the plans will be supported. How will small or singlehanded practices cope? Moving away from a didactic uniprofessional educational system immediately creates the need for a new structure to facilitate, maintain, and appraise professional and practice development plans? General practice tutors and the structures for supporting primary

1 Department of Health. A review of continuing professional development in practice: a report by the Chief Medical Officer. London: Department of Health, 1998. http://open.gov.uk/doh/cme/cmoh.htm

2 Stanton F, Grant J. The effectiveness of continuing professional development. London: Joint Centre for Medical Education, Open University, 1997.

3 Tracey JM, Arroll B, Richmond DE, Barham PM. The validity of general practitioners' self assessment of knowledge: cross sectional study. BMJ 1997;315:1426-8.

4 Davis DA, Thomson MA, Oxman AD, Haynes RB. Evidence for the effectiveness of CME. A review of 50 randomized controlled trials. JAMA 1992:268:1111-7.

5 Davis DA, Thompson MA, Oxman AD, Haynes RB. Changing physician performance. A systematic review of the effect of continuing medical education strategies. JAMA 1995;274: 700-5. care audit provide a basis for a new system and could be augmented by facilitators from the nursing and managerial professions, so that the artificial fence between "education" and "quality" may be finally dismantled. Primary care groups (and the Welsh and Scottish equivalents) could start by merging the community nursing and general medical services staff budgets and by creating and hosting development units for professional and practice development plans.

\section{Glyn Jones Elwyn Senior lecturer}

Department of Postgraduate Education for General Practice and Department of General Practice, University of Wales College of Medicine, Cardiff CF4 4XN (elwynG@cf.ac.uk)

6 Wensing M, van der Weijden T, Grol R. Implementing guidelines and innovations in general practice: which interventions are effective. $\mathrm{Br} \mathrm{J} \mathrm{Gen}$ Pract 1998;48:991-7.

7 Berwick D. A primer on leading the improvement of systems. BMJ 1996:312:619-22.

8 Bloor K, Maynard A. Rewarding healthcare teams. BMJ 1998;316:569.

9 Baker R. Characteristics of practices, general practitioners and patients related to levels of patients' satisfaction with consultations. Br J Gen Pract 1996;46:601-5.

10 Clark J, Day J, Howe E, Williams P, Biley A. Developing an immunisation protocol for the primary health care team. Health Visitor 1995;68:

11 Elwyn GJ, Rapport FL, Kinnersley P. Re-engineering the primary health care team. J Interprofessional Care 1998;12:189-98.

\section{The health of adult Europe}

\section{Combating inequalities involves measuring what counts}

$\mathrm{S}$ hortly after the change of Britain's government last year the Office of National Statistics published a volume in its decennial supplement series entitled The Health of Adult Britain 1841-1994. ${ }^{1}$ Its major aim was to bring together routine vital statistics and to chart trends in mortality. There were also many references to hospital inpatient and general practice activity data and other special data sources. In addition, many of the chapters reviewed specific areas of health or specific factors related to health. The information was collected and collated by a galaxy of authors and was well presented, but almost by definition there was nothing particularly new. One of the final chapters asked, "Are we healthier?" acknowledging that especially for the older members of our society length of life and quality of life are not the same. The answer given was that some things are better, some worse, and some have stayed the same.

However, even if the data weren't new, some of the attitudes were. The publication discussed inequalities openly if briefly and considered topics such as unemployment and housing as well as drugs, alcohol, and smoking. A little later in the year the next but one volume in the decennial supplement series from the Office of National Statistics confirmed the change of view by virtue of its title Health Inequalities. ${ }^{2}$ That volume described life and death over the millennium and reached back to 1752 for comparisons of the survival of children across Europe as well as England. It pointed out that concern about what we call inequalities lay behind the work of William Farr, the first chief medical statistician of the General Register Office (now incorporated in the Office of National Statistics), who was chiefly responsible for the tradition of collecting vital statistics enshrined in the earlier publication.

A paper published this week by Kunst et al (p 1636), ${ }^{3}$ together with earlier work to which the authors refer, indicates clearly that socioeconomic inequalities in mortality persist across Europe. Certainly variability in risk factors among different countries imposes limits on the exchange of policy experiences between these countries. But there must be a common task in developing ways to intervene against inequalities in health, and in evaluating those interventions.

It is now permissible to talk about inequalities, and it also now seems permissible to be rather more demanding about NHS and other health related information. The white paper on the new NHS in England ${ }^{4}$ says that a new information management and technology strategy for the NHS will be published in 1998 . The only details given are that the new strategy will support quality and efficiency and include accurate information about performance. The white paper also expresses a commitment to "measuring what counts"especially improvements in health-and tackling past inequalities. Various aspects of inequality are acknowledged: in health improvement, fair access, effective delivery of appropriate health care, efficiency, patients' and carers' experiences, and (last and probably the most basic and challenging) health outcomes.
Papers p 1636

BMJ 1998;316:1620-1 
A recent paper has addressed the question, "How should interventions to reduce inequalities in health be evaluated?" Clearly nationwide routine information which would provide baseline information together with information about changes would be invaluable, precisely because of the difficulty of carrying out formal research based evaluations. Many of the worthy attempts that have been made at community based evaluations have foundered because of poor quality information, ${ }^{6}$ so better routine information could be a great help. Some changes could be simple, and some extensions of our health and vital statistics systems have already been made. The Office of National Statistics reports refer to the Oxford record linkage study and to the Office of Population Censuses and Surveys' longitudinal study, which links census and registration data to produce a longitudinal sample of about $1 \%$ of the UK population. But other changes have been made in other countries which could improve the usefulness of routine information in addressing inequalities. For example, information about education was added to the US standard certificate of death in 1989 and has been used in studies of inequality and mortality. ${ }^{7}$

Can the new UK government promote new interventions? Yes-witness the proliferation of initiatives with interesting acronyms such as HAZ, HIP, as well as NICE and so on. But it is quite another question whether the new policies can be supported and evaluated by new information. Answers will involve better performance than has been shown up to now by NHS information systems. Current discussions about performance indicators are therefore crucial, and the obstacles to both conceiving and actually producing health outcome measures must be overcome, or almost all will be lost. A small but increasing number of clinically experienced medical informatics specialists in Britain and Europe-in collaboration with North American colleagues-have much to offer but a heavy responsibility also. Addressing inequalities involves interdepartmental cooperation within Whitehall: how about addressing health information in a similar cooperative way? Can the efforts of the staff of the Office of National Statistics and their band of collaborators from all around Britain (who have produced reports such as the two supplements described above) be better coordinated with the Department of Health and the NHS Executive, especially with the research and development programme?

However, the words of wisdom of the programme committee on socioeconomic inequalities in health in the Netherlands should be heeded: "Evaluating interventions to reduce inequalities in health is likely to be complicated and expensive. This message will not please policy makers, but if one is serious about reducing inequalities in health one should also be serious about assessing the actual attainment of the objectives." ${ }^{5}$

Stuart Donnan Consultant in public health medicine

Lambeth, Southwark and Lewisham Health Authority, London SE1 7NT

1 Charlton J, Murphy M, eds. The health of adult Britain 1841-1994. London: Stationery Office, 1997. (Office for National Statistics series DS No 13.)

2 Drever F, Whitehead M, eds. Health inequalities. London: Stationery Office, 1997. (Office for National Statistics series DS No 15.)

3 Kunst AE, Groenhof F, Mackenbach JP, and the EU Working Group on Socioeconomic Inequalities in Health. Occupational class and cause specific mortality in middle aged men in 11 European countries: comparison of population based studies. BMJ 1998;316:1636-42.

4 Secretary of State for Health. The new NHS . London: Stationery Office, 1998. (Cm 3807.)

5 Mackenbach JP, Gunning-Schepers LJ. How should interventions to reduce inequalities in health be evaluated? J Epidemiol Comm Health 1997;51:359-64.

6 Arblaster L, Entwistle V, Lambert M, Forster M, Sheldon T, Watt I. Review of research on the effectiveness of health service interventions to reduce variations in health. York: NHS Centre for Reviews and Dissemination, 1995.

7 Christenson BA, Johnson NE. Educational inequality in adult mortality: an assessment with death certificate data from Michigan. Demography $1995 ; 32: 215-29$

\section{Applying research evidence to individual patients}

\section{Evidence based case reports will help}

Clinical review p 1660
$\Lambda$ t the heart of clinical medicine is an unresolved conflict-between the essentially case based nature of clinical practice and the mainly population based nature of the research evidence. While clinicians are exhorted to use up to date research evidence to give patients the best possible care, actually doing so in individual patients is difficult. The reasons are well known. ${ }^{1}$ The research literature is poorly organised, ${ }^{2}$ largely of poor quality and irrelevant to clinical practice, ${ }^{3}$ often conflicting, and often not there at all. ${ }^{4}$ The most valid and, at first sight, relevant information may be based on highly selected groups of patients bearing little resemblance to the patient in front of you. And statistical probabilities may mean little to you or your patient. Steering your way through the evidence jungle takes time, skill, and perseverance.

To help readers develop the increasingly necessary art of using research evidence in practice, the $B M J$ is launching a new type of article-the evidence based case report. In the first of these (p 1660), Glasziou describes how searching and interpreting the published literature helped him to reach an informed diagnosis in a woman with a chronic cough. ${ }^{5}$

Evidence based case reports will attempt to show how evidence can be applied at all stages of patient care. Information from cohort studies about the frequency of different conditions can suggest the most likely diagnosis. Decisions about which tests to order can be guided by information on the sensitivity and specificity of different tests and, in the case of invasive tests, their adverse effects and acceptability to patients. Decisions about which interventions to advise, if any, can be informed by randomised controlled trials and systematic reviews looking at the comparative effectiveness, safety, and acceptability of the various options. Information on long term or rare side effects can be 
gleaned from well designed cohort or case control studies. When a thorough search of the literature fails to find appropriate, high quality evidence, the case reports' contributors are encouraged to say so, since it may be helpful to know that the gaps are in the evidence rather than in your own knowledge.

Case reports have long been used to report new findings and to give educational impact to review articles. Evidence based case reports will not report new findings. General medical journals have largely stopped publishing original case reports of this sort, recognising that these can give a clinical audience no reliable information on the cause of a condition, its prognosis, the usefulness of a diagnostic test, or the effectiveness and safety of an intervention. Exceptions to this rule are reports dealing with adverse events, where journals have a duty to report any reasonable information they receive. This includes case reports in which the adverse event might be reasonably linked to an intervention on the basis of temporal relation, dose response relation, reversibility on withdrawal, recurrence on rechallenge, or physiological rationale.

Instead of presenting new findings, evidence based case reports are intended to illustrate a process. Contributors are being asked to take an approach now familiar to students of critical appraisal-to define the clinical question; search the literature for studies of appropriate relevance, design, and quality; apply the information; and audit the result. ${ }^{7}$ Explicit methods will allow readers to see how the authors reach their conclusions. Because they will be based on real patients seen by generalist clinicians in primary and secondary care, the case reports will also, we hope, provide reliable updates on the management of common clinical problems.

The first few evidence based case reports have been commissioned, but we hope many others will be submitted. All published contributions will be peer reviewed. We prefer reports on common or important conditions relevant to a general clinical audience. Guidance to contributors will shortly be appearing on the BMJ's website (www.bmj.com).

Fiona Godlee Assistant editor, BMJ

1 Haynes RB. Some problems applying evidence in clinical practice. In Warren KS, Mosteller F, eds. Doing more good than harm: the evaluation of health care interventions. New York: New York Academy of Sciences, 1993:210-25.

2 Smith R. The clinical information needs of doctors. $B M J$ 1996;313:1062-8

3 Haynes RB. Where's the meat in clinical journals? ACP Journal Club 1993;119:A22-3

4 Office of Technology Assessment of the Congress of the United States. The impact of randomised controlled trials on health policy and medical practice. Washington DC: US Government Printing Office, 1983.

5 Glasziou P. Twenty year cough in a non-smoker. BMJ 1998:316:1660-1.

6 McDermott MM, Lefevre F, Feinglass J, Reifler D, Dolan N, Potts S, et al. Changes in study design, gender issues, and other characteristics of clinical research published in three major medical journals from 1971 to 1991. J Gen Intern Med 1995;10:13-8.

7 Sackett DL, Richardson WS, Rosenberg W, Haynes RB. Evidence based medicine: How to practise and teach EBM. Edinburgh: Churchill Livingstone, 1997.

\section{Renegotiating medicine's contract with patients}

\section{The GMC is leading the way}

$\mathrm{T}$ he social contract between doctors and the public is being renegotiated. The contract says in essence: "In return for guaranteeing that we will be treated by competent doctors who will respect our dignity and offer us services better than those of the local garage we the public will give you doctors status, above average incomes, and the privilege of regulating yourselves." The contract is renegotiated not by bald men in suits in back rooms but rather by the public expressing its disquiet in a myriad of forms - through, for example, parliament, the media, and patients' organisations-and by the profession recognising the disquiet and responding. The BMA, the Academy of Medical Royal Colleges, and postgraduate and undergraduate deans last month produced a report on improving self regulation at the local level, ${ }^{12}$ while the Royal College of Physicians of London has before it a document that calls on it to "put in place urgently evidence that robust mechanisms exist for self regulation of its members and fellows." ${ }^{3}$ But it is the General Medical Council that is in the front line of negotiation. If it falls, then self regulation will be lost.

These are momentous times at the GMC. The long running case of the Bristol doctors who are accused of failing to warn patients about poor surgical results will probably have ended by the time you read this. The judgment, whichever way it goes, is likely to be accompanied by a debate on the effectiveness of the GMC. The debate has certainly been building while the case has been underway. ${ }^{4}$ Away from the limelight of the Bristol case the council last week approved (with some minor amendments) the document Good Medical Practice that sets the standards that doctors are expected to meet. ${ }^{5}$ If doctors don't meet the standards then their registration may be removed.

The most important thing about Good Medical Practice is that it sets standards in a positive way. It says what doctors should do, not what they shouldn't do. Moses never got so far, and the document is a vital step forward. It is a part of the negotiation that is likely to preserve self regulation.

Ian Kennedy-professor of law, one time scourge of the medical profession, and a former member of the GMC-was arguing 10 years ago that doctors needed specific guidelines on what constituted good practice. ${ }^{6}$ In those days he was a voice in the wilderness. Doctors responded that such guidelines would be impossible because medicine was too inexact. Besides such guidelines would need enormous amounts of time and skill 
to produce and would lead to a restricted and defensive style of practice. Kennedy, who believed that "the jury is still out on whether self regulation by doctors is adequate" also argued that the GMC would have to insist on reregistration and the establishment of an inspectorate. The council has yet to go so far, but the continuing renegotiation of the social contract might require it. The profession certainly needs to show that its members are keeping up with the latest evidence and maintaining their skills. The abundant evidence that the practice of many doctors is not in line with the best evidence has been the main force leading to clinical governance, the government's concept of the boards of trusts being as responsible for clinical performance as they are for financial and legal performance.

Although many doctors 10 years ago were sceptical of the practicality of and need for guidelines on good practice, the Royal College of General Practitioners had already made important steps forward with its reports on What Sort of Doctor $?^{78}$ (Sir Donald Irvine, the current president of the GMC and the driving force behind Good Medical Practice, was one of the leaders of the Royal College of General Practitioners in those days.) The professional examinations set by the colleges are educationally meaningless unless it is possible to define what constitutes a good general practitioner, physician, surgeon, or whomever. Good examinations need such definitions. Otherwise, they are as pointless as diagnostic methods where there is no gold standard. Colleges are increasingly recognising this and producing definitions. The Senate of Surgery of Great Britain and Ireland last October, for instance, published The Surgeon's Duty of Care. ${ }^{9}$
All of these documents emphasise what might be called the "softer side of medicine"-communication, ethical behaviour, treating patients with dignity, and being a team player. All medical students have met the stereotype of the brilliant diagnostician or the outstanding surgeon who is rude to patients, bullies students, and exploits colleagues. It may still be possible to be such a creature and be a successful conductor, footballer, or poet, but it's not acceptable in medicine. Patients and the public expect much more, and doctors must deliver.

Just as anybody starting a job will read their contract carefully so every doctor in Britain should read Good Medical Practice. This is your social contract with patients and the public. You might read it to avoid the shame of having to tell the professional conduct committee of the GMC or a court that you haven't-but much better read it to a feel a thrill of pride in your profession and calling.

Richard Smith Editor, BMJ

1 BMA, Academy of Medical Royal Colleges, COPMED, Committee of Undergraduate Deans. Making self regulation work at a local level. London: BMA, 1998

2 Beecham L. Self regulation of doctors must work locally. BMJ 1998;316:1477.

3 Working Party on Functions and Structures of the Royal College of Physicians. Report. London, RCP, 1998.

Smith R. GMC under the cosh. BMJ 1998;316:946

5 General Medical Council. Good medical practice. London: GMC, 1998

6 Kennedy I. Quoted in: Smith R. Profile of the GMC. The day of judgment comes closer. BMJ 1989;298:1241-4.

7 Royal College of General Practitioners. What sort of doctor? JR Coll Gen Pract 1981;31:698-702.

8 Royal College of General Practitioners. What sort of doctor? Assessing quality of care in general practice. London: RCGP, 1985.

9 Senate of Surgery of Great Britain and Ireland. The surgeon's duty of care. London: Senate of Surgery of Great Britain and Ireland, 1997.

\title{
Medical ethics and law as a core subject in medical education
}

\author{
A core curriculum offers flexibility in how it is taught-but not that it is taught
}

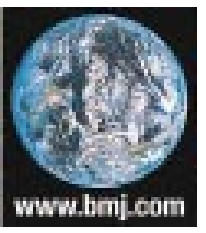

The full core curriculum appears on our website

BMJ 1998;316:1623-4
I n Tomorrow's Doctors Britain's General Medical Council initiated a radical and needed reform of medical education. One of the less noticed, yet revolutionary, aspects of this reform is that medical ethics and law have become a core component of the curriculum. Thus all medical students, states the council, must acquire knowledge and understanding of ethical and legal issues relevant to the practice of medicine and be able "to understand and analyse ethical problems so as to enable patients, their families, society, and the doctor to have proper regard to such problems in reaching decisions."

Seeking to pool their expertise, most of the academics currently teaching medical ethics and law in UK medical schools-mostly clinicians, philosophers, lawyers, and theologians-hammered out a consensus statement about what should constitute the core academic content necessary to produce "doctors who will engage in good ethically and legally informed practice." They also agreed some minimal organisa- tional requirements for the subject to be taught successfully.

The consensus statement sees the teaching of medical ethics and law as contributing to the overall objective of medical education-"the creation of good doctors who will enhance and promote the health and medical welfare of the people they serve in ways which fairly and justly respect their dignity, autonomy and rights." To achieve these goals medical students must be able to understand the ethical principles and values underpinning good medical practice; be able to think critically about ethics, reflecting on their own beliefs and understanding and appreciating alternative, perhaps competing, approaches; and "be able to argue and counterargue in order to contribute to informed discussion and debate." Students must know the main professional and legal obligations of doctors in the UK, especially those specified by the General Medical Council, and be able constructively to participate in the ethical and legal reasoning needed in everyday practice. 


\section{Editorials}

We cannot detail here all the recommendations of the consensus statement. It, and the names of those who created it, are available on the BMJ's website (www.bmj.com) and will be published in the Journal of Medical Ethics. ${ }^{2}$ The box, however, outlines the 12 agreed themes of the proposed core curriculum, along with an indication of some of the ethical and legal topics encompassed by those themes, all of which the consensus document proposes must be taught.

The consensus group states explicitly that its specification of the content of these core issues is not intended to prejudge how they are to be taught, but one way or another "all the topics specified ought to be addressed." Equally, there was unanimous agreement that, whileteaching of this subject should be widely shared within medical schools, its adequate provision and coordination require at least one full time senior academic in ethics and law with relevant professional and academic expertise-for the subject is "an emerging academic discipline with intrinsic and rigorous standards." Medical ethics and law can no longer be taught by well disposed clinicians without some consistent interaction with and support from specialists.

The consensus group recommends that medical ethics and law should be introduced systematically, should feature throughout the entire clinical curriculum (right through to the house officer year), and should be fully integrated within it. Such integration should include each clinical discipline addressing ethical and legal issues of particular relevance to that discipline, especially those which students will have personally encountered on their course. Finally, the competence of both students and teachers should be formally assessed, with the same rigour as for any other core subject.

The proposed curriculum is a full one, and each medical school is likely to implement it differentlywhich to non-hegemonists is one of the strengths of the document. What the consensus group regarded as non-negotiable, however, is the need to implement all of it. The burden must fall on those who reject any component of the proposed core curriculum to explain why a newly qualified doctor does not need to understand it. We have no doubt ourselves that the interests of medical students, the medical profession, patients, and the community at large converge in urging stiff resistance to any attempts to reduce what the consensus group sees as the minimal content of a core curriculum for medical education in medical ethics and law.

\section{Len Doyal Professor of medical ethics}

St Bartholomew's and the Royal London School of Medicine and Dentistry, Queen Mary and Westfield College, University of London, London E1 2AD

\section{Raanan Gillon Professor of medical ethics}

Imperial College School of Medicine, University of London, London SW7 2AZ

\section{Core curriculum for medical ethics and law}

(1) Informed consent and refusal of treatment -Why respect for autonomy is so important; adequate information; treatment without consent; competence; battery and negligence.

(2) The clinical relationship:truthfulness, trust, and good communication -Ethical limits of paternalism; building trust; honesty, courage, and other virtues in clinical practice; narrative and the importance of communication skills.

(3) Confidentiality-Clinical importance of privacy; compulsory and discretionary disclosure; public $v$ private interests.

(4) Medical research -Ethical and legal tensions in doing medical research on patients, human volunteers, and animals; the need for effective regulation.

(5) Human reproduction -Ethical and legal status of the embryo/fetus; assisted conception; abortion, including prenatal screening.

(6) The new genetics-Treating the abnormal $v$ improving the normal; debates about the ethical boundaries of and the need to regulate genetic therapy and research.

(7) Children-Ethical and legal significance of age to consent to treatment; dealing with parental/child/ clinician conflict; child abuse.

(8) Mental disorders and disabilities - Ethical and legal justifications for detention and treatment without consent; conflicts of interests between patient, family, and community.

(9) Life, death, dying, and killing-The duty of care and ethical and legal justifications for the non-provision of life prolonging treatment and the provision of potentially life shortening palliatives; transplantation, death certification, and the coroner's court.

(10) Vulnerabilities created by the duties of doctors and medical students - Public expectations of medicine; the need for teamwork; the health of doctors and students in relation to professional performance; the General Medical Council and professional regulation; responding appropriately to clinical mistakes; whistleblowing.

(11) Resource allocation -Ethical debates about "rationing" and the fair and just distribution of scarce health care; the relevance of needs, rights, utility, efficiency, desert, and autonomy to theories of equitable health care; boundaries of responsibility of individuals for their own health.

(12) Rights-What rights are, and their links with moral and professional duties; the importance of the concept of rights, including human rights, for good medical practice.
General Medical Council. Tomorrow's doctors. London: GMC, 1993.

2 Consensus Group of Teachers of Medical Ethics and Law in UK Medical Schools. Teaching medical ethics and law within medical education: a model for the UK core curriculum. J Med Ethics 1998;24:188-92. 